\title{
Field tests of a timber queen-post truss and numerical analysis
}

\author{
J.M. Branco \& P.J.S. Cruz \\ Civil Engineering Department, ISISE, University of Minho, Portugal
}

M. Piazza

University of Trento, Trento, Italy

H. Varum

University of Aveiro, Aveiro, Portugal

\begin{abstract}
In-situ cyclic tests on an existing traditional timber truss were performed. The main goal of the tests was to evaluate the overall behavior of the timber truss under symmetric and non-symmetric loading. Moreover, the influence of the location of point loads application, without and with eccentricity relatively to joints, was assessed. The carrying tests were preceded by a visual and non-destructive inspection aiming to collect geometric data and to assess the decay level. The field tests results of a queen-post truss are presented and analyzed. A numerical model was developed to reproduce the test results.
\end{abstract}

\section{INTRODUCTION}

The lack of practical, but realistic, numerical models for the simulation of the behaviour of joints in traditional timber structures normally leads to the replacement of old roof structures, instead of their retrofitting to satisfy safety and serviceability requirements present in recent Codes and Recommendations. Moreover, the misunderstanding of the global behavior of traditional timber roof structures can result in unacceptable stress distribution in the members, as a result of inappropriate joints strengthening (in terms of stiffness and/or strength). To overcome this need, laboratory tests on scaled or full-scale specimens of members, connections and trusses can be done. However, only with field-tests the behavior in real conditions can be evaluated.

Field tests on traditional timber trusses are not common. Researchers (Del Senno 2003; Piazza et al., 2004; Branco et al. 2008) have preferred to transport the full-scale specimens to laboratory. In-situ working conditions are a barrier and the setup implementation (measurement system and load application) is often difficult.

The work presents the field test results of a timber queen-post truss under symmetric and non-symmetric loading. The influence of the number of point loads was studied. The truss has been characterized with regard to geometry, material properties, material decay using non-destructive tests methods. A numerical analysis has been developed to reproduce the test results.

\section{TRUSS ASSESSMENT}

The queen-post timber truss evaluated belongs to the roof structure of an old warehouse of Adico industry, located at Avanca (55 km South from Oporto). The exact date of the construction is not known but the industry exists since 1920 and some plans of the village from 1942 already show the warehouse. Trusses are the main elements of the roof structure, covered with ceramic tiles, $27^{\circ}$ slopes and rafters spaced $50 \mathrm{~cm}$ over the purlins and the ridge. The free span of the trusses is $11.8 \mathrm{~m}$ and the average distance between their centres is $3.5 \mathrm{~m}$.

The geometry of the truss is particular: the configuration is typical of a king-post truss, but queen-posts were added connecting the joint strut/rafter to the tie-beam. This is not the traditional queen-post truss geometry, in which the king-post is substituted by a straining beam connecting horizontally (in the upper part) the two queen-posts, those located below the higher purlins, and the struts connecting the bottom part of the queen-posts to the lower purlins. Clearly, it is an example of a timber truss with an incorrect configuration for the span of the roof. The correct queen-post truss geometry should have been used or two extra posts (princess-posts) should have been 


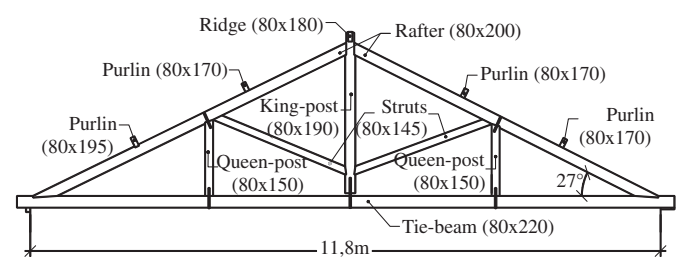

Figure 1. Truss geometry.

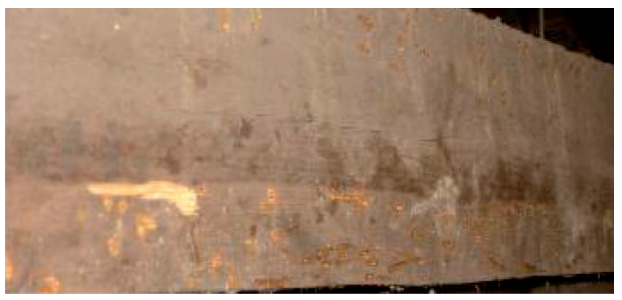

Figure 2. Emergence holes over the surface of sapwood.

located below the lower purlin. Point loads out of the joints, causing bending moments in the rafters, are the most common error detected in the preliminary survey performed in previous steps of the research program (Branco et al. 2006).

The truss is made of maritime pine (Pinus pinaster, Ait.). The timber members of the truss are slender, as characteristic of traditional Portuguese roofs structures, with cross-sections varying from $80 \times 145 \mathrm{~mm}^{2}$ for the struts to $80 \times 220 \mathrm{~mm}^{2}$ for the tie-beam. The tie-beam is suspended to the posts by iron straps nailed into the posts. Between the tie-beam and the king-post there is a gap of $5 \mathrm{~cm}$ while queen-posts are in contact with the tie-beam. Connections between the others timber members are made by single step joints, in some cases nailed, and the queen-posts/rafters connections have a heel strap nailed ( $25 \mathrm{~mm}$ wide and $5 \mathrm{~mm}$ tick), Figure 1.

Despite the apparent good condition of the timber members of the truss, the visual inspection revealed insects attack in the tie-beam, queen-posts and struts. In these timber members, emergence holes over the surface of sapwood are visible however, without signs of active infestation, Figure 2.

To evaluate the extension of decay in the timber truss, Pilodyn ${ }^{\circledR}$ and Resistograph ${ }^{\circledR}$ non-destructive tests were performed. The Pilodyn $6 \mathrm{~J}$ was used with the aim to assess the surface hardness through the depth penetration of the pin steel $(2.5 \mathrm{~mm})$ measured in each test performed. Resistograph permits to plot profiles (drill resistance versus penetration depth) that can be used to determine the location and extent of voids, allowing the calculation of the residual cross section (since decayed wood presents lower penetration resistance), and variation in material density.

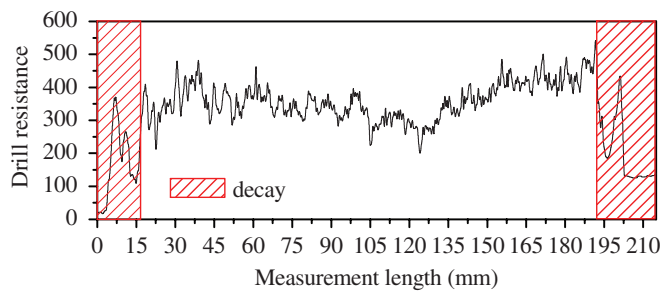

Figure 3. Calculation of the cross-section reduction based in a Resistograph test profile.

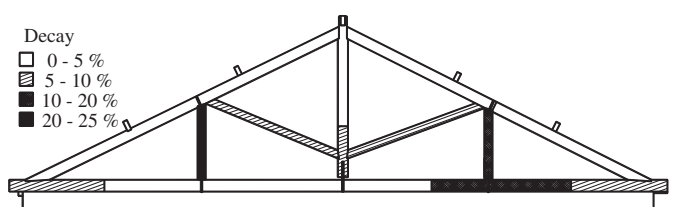

Figure 4. Map of the decay extension in the truss.

\section{TEST SETUP, INSTRUMENTATION AND PROCEDURE}

The main goal of the tests was to evaluate the overall behavior of the timber truss selected under symmetric and non-symmetric loading. Moreover, the influence of the location of point loads application, without and with eccentricity relatively to joints, was assessed.

This is the consequence of the roof geometry, which exhibits two purlins located with an eccentricity relatively to the intermediate joint of the rafter. Therefore, firstly, joints loads were applied in the joints $\left(F_{1}, F_{2}\right.$ and $\mathrm{F}_{3}$ ) and, in a second step, loads were applied over the purlins and ridge $\left(\mathrm{F}_{1}, \mathrm{~F}_{4}, \mathrm{~F}_{5}, \mathrm{~F}_{6}\right.$ and $\left.\mathrm{F}_{7}\right)$.

Loading and unloading were recorded and an attempt to measure the creep of the structure under symmetric loading was made. The behavior of the truss under non-symmetric loading was evaluated, in the first scheme, only by one test and in the second with two tests (one in each pitch side). Table 1 resumes the tests performed.

Wood pallets suspended to the truss by four steel cables $(\phi 6 \mathrm{~mm})$ supported the $35 \mathrm{~kg}$ cement bags used as loads. Each loading and unloading procedure was divided in steps of $175 \mathrm{~kg}$ ( $5 \mathrm{bags})$. A total load of $2625 \mathrm{~kg}(3 \times 875 \mathrm{~kg})$ and $2975 \mathrm{~kg}(5 \times 595 \mathrm{~kg})$ was used in the first (three point loads) and second (five point loads) schemes, respectively. The difference in the maximum load value applied between both schemes, $350 \mathrm{~kg}$, is due to the difficulty to increase the number of bags over the pallets in the first case. To record the deformation of the truss during the tests, eight LVDTs (Linear Variable Differential Transformer) and six dial gauges (DG) were used. LVDTs were responsible for measuring the 
Table 1. Summary of the tests performed.
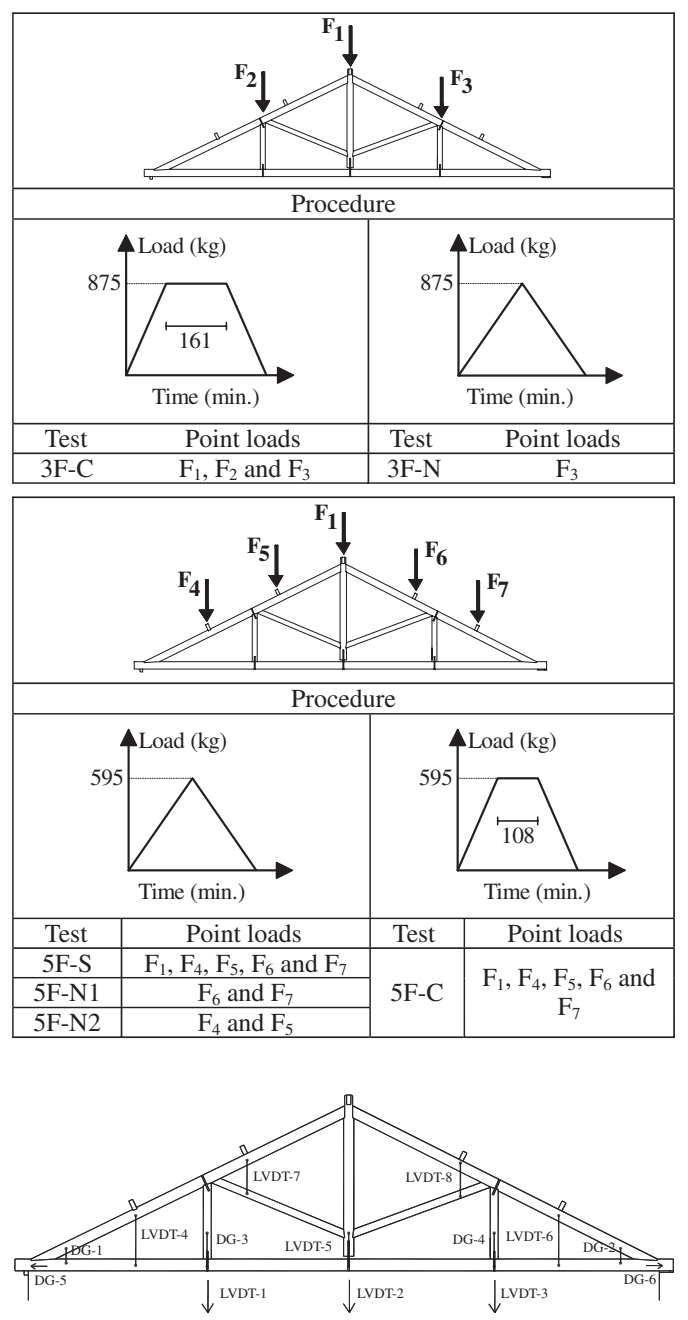

Figure 5. Instrumentation of the tests. Eight LVDTs and six DGs.

global displacement (LVDTs 1 to 3 ), the behavior of the king-post/tie-beam connection (LVDT-5) and the displacement below the purlins (LVDTs 4 to 8 ) also used to calculate the rotational behavior of the joints rafter/tie-beam and rafter/strut. The values of the LVDTs during the tests were acquired by a Data Acquisition System, with 8 channels, using a LabVIEW program (version 8.2). Dial gauges measured the opening of the queen-post/tie-beam connections (DG 3 and 4), the horizontal displacement of the rafter in the rafter/tie-beam connections (DG 5 and 6) and two additional points to calculate the rotation of rafter/tiebeam connections (DG 1 and 2). Figure 5 shows the instrumentation used in the tests performed.

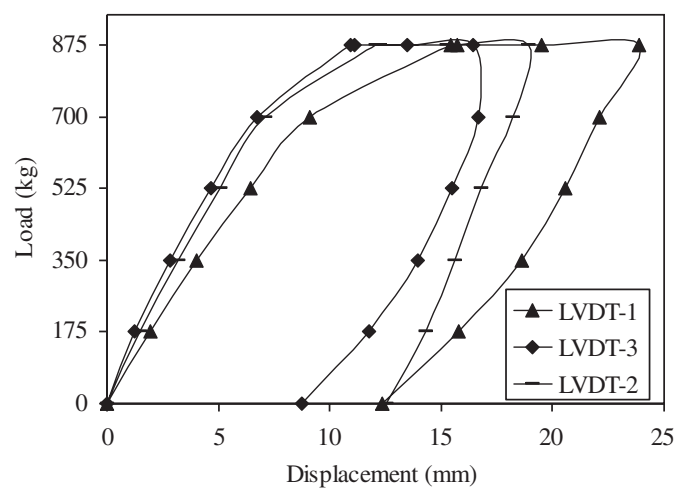

Figure 6. Displacement recorded by LVDTs 1, 2 and 3 during 3F-C test.

In every loading and unloading step the displacement values of the LVDTs were recorded; however, in the case of the dial gauges, only some steps were acquired, as results of the little variation verified.

\section{ANALYSIS OF THE TEST RESULTS}

The behavior of the traditional timber trusses even under symmetric loading is non-symmetric. The response of traditional timber trusses is highly depending on the variability of the timber member crosssections, material properties, connections, supports and loading conditions. When using a natural and anisotropic material like wood, it was impossible for carpenters, sometimes in extremely difficult working conditions, to avoid that variability during construction. Moreover, in the case of old constructions, due to decay processes and lack of maintenance, this heterogeneity is emphasized.

The field test results confirm that the truss under investigation presents a non-symmetric behavior even when subjected to symmetric loading conditions, Figure 6.

The difference observed between the displacementload curves of LVDT's 1, 2 and 3 can represent the influence of the decay observed in the left queen-post. The constant load rate applied during 161 minutes (see Table 1) results in a deformation increment of the truss (creep). The truss presents important plastic deformations (average value of 57\%) after the complete unloading. The king-post/tie-beam connection works effectively, i.e. the tie-beam is suspended to the king-post, Figure 7.

The heel strap is able to suspend the tie-beam, reducing therefore the deformation of this element (see Figure 6 LVDT-2), and presents also creep, however, less than the one presented by the wood members. The connections between the queen-posts and the 


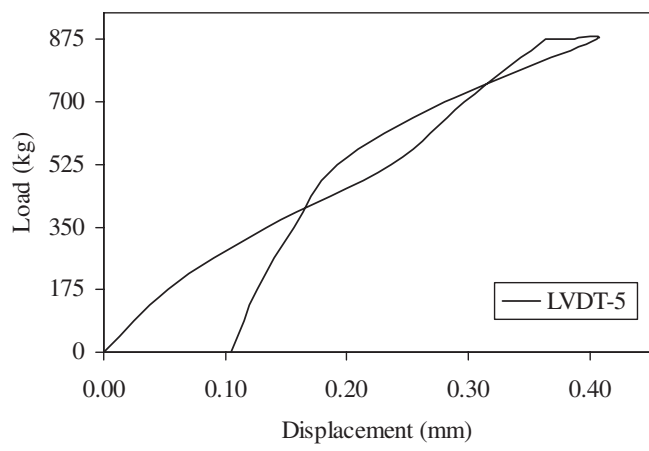

Figure 7. Behavior of the king-post/tie-beam connection during $3 \mathrm{~F}-\mathrm{C}$ test.

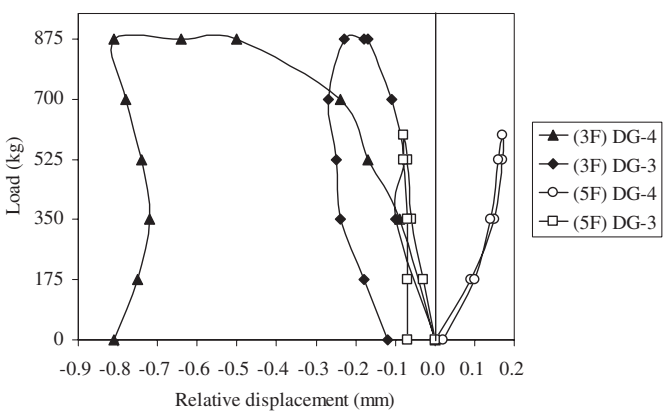

Figure 8. Behavior of the left rafter/tie-beam connection during $3 \mathrm{~F}-\mathrm{C}$ test. Negative values are recorded when the two elements are approaching.

tie-beams, where a heel strap suspended the tie-beam, show different behaviors, Figure 8. Only the left connections, measured by DG-3, in the second series of tests ( $5 \mathrm{~F}, 5$ point loads), behave properly - the tie-beam is suspended to the queen post. In the first series of tests, both connections show plastic behaviour. Therefore, it can be concluded that, before the tests, those connections were dismantled. The first series of tests were sufficient for the left connections to recover, while the gap between both connected elements existing in the right connection was never recovered.

During the $3 \mathrm{~F}-\mathrm{C}$ test, significant damage was detected on the left rafter/tie-beam connection, over the DG-7, (Figure 9a). Damage started for a point load level of $700 \mathrm{~kg}$ and with $850 \mathrm{~kg}$ the measurement of the DG-7 only became stable after 30 minutes. At the end of the loading period, the maximum relative horizontal displacement between the rafter and the tie-beam (measured by DG-7) was reached and no recover was observed during and after the unloading procedure, Figure $9 b$

Under non-symmetric loading, as the one imposed during the test $3 \mathrm{~F}-\mathrm{N}$, distortion of the truss is observed,

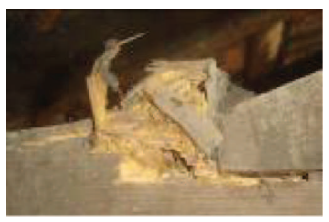

(a) Damage

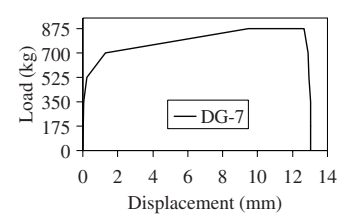

(b) load-displacement curve of DG-7
Figure 9. Behavior of the left rafter/tie-beam connection during $3 \mathrm{~F}-\mathrm{C}$ test.

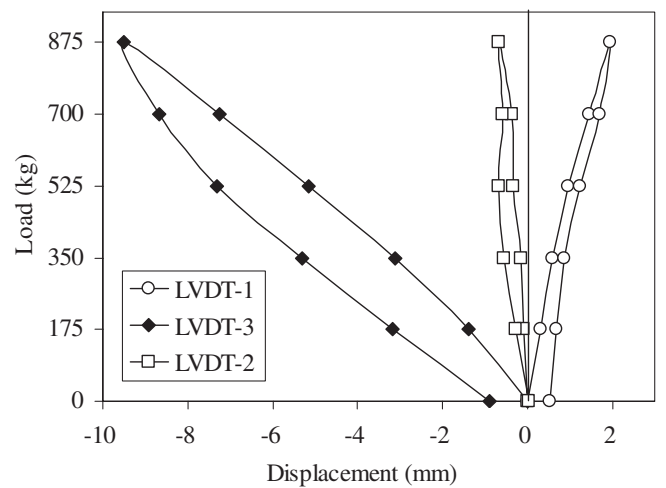

Figure 10. Displacement recorded by LVDTs 1, 2 and 3 during $3 \mathrm{~F}-\mathrm{N}$ test.

in particular, in the tie-beam, as shown in Figure 10. Non-symmetric behavior is acquired by LVDT-1 and 3 with lower values in the first LVDT as consequence of the bigger stiffness (compression of the left queenpost).

Dividing the total amount of load applied by more point loads in the second tests series, from 3 to 5 , the same general conclusions about the asymmetric behavior of the truss, even when subjected to symmetric loading, can be drawn. The main difference between the tests under 3 and 5 point loads is, in the second case, the introduction of significant bending stresses in the rafters.

As a consequence, greater values of rotation in the connections are obtained (Figure 11) while the global displacements are lower (Figure 12), when compared with the 3 point loads case. In the first case the system is more rigid.

Applying the loads with eccentricity relatively to joints, the main stresses are found in the rafters, caused by bending, and greater rotations of the rafter/struts and rafter/tie-beam are obtained. When the point loads are applied directly in the joints, the main stresses are observed in queen-posts (compression), pushing the tie-beam down. As a consequence, LVDTs 1, 2 and 3 show higher values of displacement, Figure 12. In addition, the creep behavior observed in the case of 


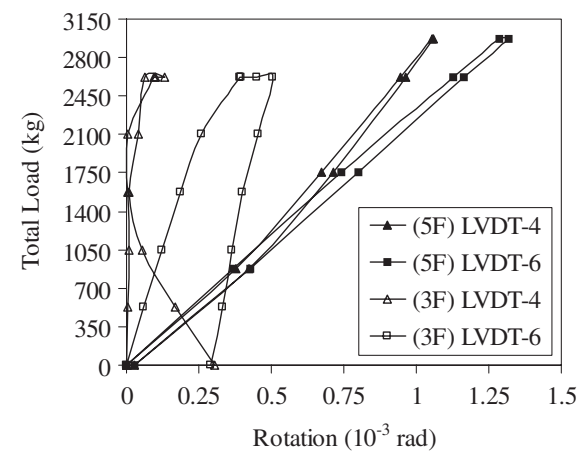

Figure 11. Comparison between rotations calculated based on values recorded by LVDTs 4 and 6 during $3 \mathrm{~F}-\mathrm{C}$ and $5 \mathrm{~F}-\mathrm{S}$ tests.

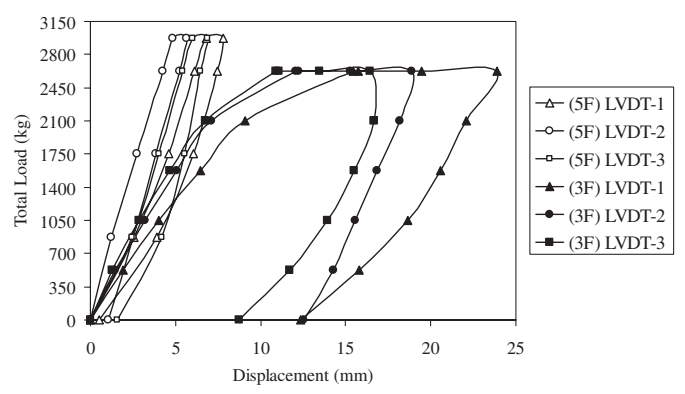

Figure 12. Comparison between the displacements recorded by LVDTs 1,2 and 3 during $3 \mathrm{~F}-\mathrm{C}$ and $5 \mathrm{~F}-\mathrm{C}$ tests.

three point loads (3F-C) is significantly greater but, in this case, the influence of the damages observed in the rafter/tie-beam connection must be taken into account.

\section{NUMERICAL ANALYSIS}

The structural analysis program SAP 2000 has been used to model the tests. It has been developed a model involving variable dimensions beam elements, and semi-rigid joints between the different elements, assuming anyway a linear behavior of the material.

\subsection{Material model}

Timber is assumed as an orthotropic material in the system so-called anatomic cylindrical coordinates corresponding to the longitudinal, $L$, radial, $R$, and transversal, $T$, directions of the tree trunk. Cylindrical coordinates may be approximated as orthogonal, for the material extracted from the outer region of the trunk. The elastic modulus, for an asymmetric model, are $E_{0}$ in the direction along the fibers, and
$E_{90}$ orthogonal to it, plus a shear modulus, $G$, and a Poisson's ratio, $v$. For the material properties values the LNEC (1997) was followed.

\subsection{Geometric and mechanical models}

The geometry and loading of the truss permits the assumption of a state of plane stress for the model. The truss is analyzed as a frame structure, having the member an elastic behavior while a semi-rigid behavior has been assumed for the connections. The semi-rigid behavior of the connections is introduced in the model with the Nonlinear link elements (Nlink).

\subsection{Loads}

During the tests two types of loads were applied in the structure. Uniformly distributed loads representing the self-weight of the truss member, automatically computed, and joint loads as result of the self-weight of the roof structure, transmitted to the truss by the purlins, and the ones applied during the different load procedures of the tests performed.

\subsection{Semi-rigid modeling of connections}

Traditional timber joints, even without any strengthening device, usually have a significant moment capacity. Common constraint models, like hinges or full restraint connections, indeed, cannot satisfactorily describe the real behavior of these joints. The joint behavior may be classified as semi-rigid and, being based on friction, is influenced by the time-varying level of compression between the joined members (Parisi \& Piazza 2000). In order to properly describe this behavior, the elastic stiffness of each Nlink must be defined, according to the different geometric and mechanical features of the elements at each joint.

Candelpergher \& Piazza (2001) have proposed some expressions to define the rotation stiffness of traditional timber connections, however, these rules should be verified for the Portuguese traditional timber connections case. Because this calibration process is not yet finished, only the symmetric tests will be numerically analyzed. In the case of the symmetric tests performed the rotation stiffness of connections has a trivial influence in the overall behavior of the tested truss. However, the axial stiffness of the connections is crucial in the truss response (deformation and stress distribution).

The axial stiffness $\left(k_{a x}\right)$ depends from the lumber mechanical properties, the geometric proportions of the connected elements and the connection angle (skew angle):

$k_{a x}=\frac{E_{\alpha} S}{l}$ 
where, applying the Hankinson Equation (2):

$$
E_{\alpha}=\frac{E_{0}}{\cos ^{2} \alpha+\frac{E_{0}}{E_{90}} \sin ^{2} \alpha}
$$

represents the wood elastic modulus in the direction forming an angle $\alpha$ with the fiber.

$$
l=\frac{h}{2 \sin \alpha}
$$

represents the nominal notch length, where compression deformation occurred.

$$
S=\frac{A_{\text {rafter }}}{\sin \alpha}
$$

represents the nominal notch area, where stress was assumed to be transmitted.

The axial stiffness of the tie-beam/posts connections $\left(k_{a x, h s}\right)$ has been formulated taking into account the axial stiffness of the heel strap:

$k_{a x, h s}=\frac{E_{\text {steel }} A_{\text {heel strap }}}{l_{\text {heel strap }}}$

where $E_{\text {steel }}$ is modulus of elasticity of steel, $A_{\text {heelstrap }}$ and $l_{\text {heelstrap }}$ is the cross-section and the length of the heel strap, respectively.

\section{NUMERICAL VERSUS EXPERIMENTAL RESULTS}

Numerical modeling and experimental results have been compared in the case of the symmetric tests. First, Step 0, the numerical model has been implemented without considering the real behavior of the truss observed in the performed tests. Then, the model was verified and calibrate based in the tests results (Step 1).

Assuming the axial stiffness at the connections given by Equations 1 to 5, Step 0, the computed values for the global displacements (LVDT 1 to 3 ) represents only $33 \%$ of the test results obtained for the first test (3F-C). The main reason for this difference is the fact that all connections, in particular the ones between the posts and the tie-beam, showed significant gaps between the metal devices and the joint itself. Moreover, the deterioration and loss of strength of the steel elements are not considered in the calculated stiffness values. The gaps between the metal devices and the joints are confirmed by the tests results (see Figures 7 and 8). It is also important to

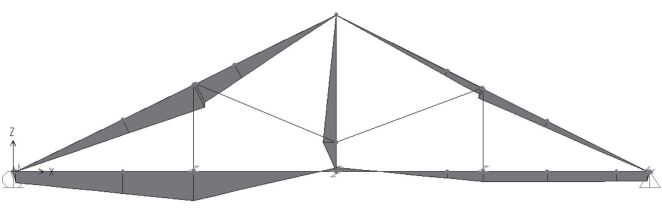

Figure 13. Bending moment on the truss in the 3F-C test.

point out that the plastic deformation measured in the global displacement after the 3F-C test represents $52 \%, 66 \%$ and $53 \%$ of the maximum displacement, respectively for LVDT 1, 2 and 3. In the case of the relative displacements measured in the tie-beam/posts connections, the residual values represents $57 \%, 100 \%$ and $52 \%$ of the maximum displacement recorded at LVDT-5, DG-3 and DG-4, respectively. Therefore, the stiffness values calibrated for the first tests performed, $3 \mathrm{~F}-\mathrm{C}$, should be only account as informative because they report the influence of the original gaps existing between the metal devices and the joints. It is important to note that during the first test, $3 \mathrm{~F}-\mathrm{C}$, a significant damage of the left rafter/tie-beam connections was detected (Figure 9) which influences directly the global displacements values.

However, the calibrated model was able to reproduce the non symmetric response of the truss even under symmetric loading conditions applied during the $3 \mathrm{~F}-\mathrm{C}$ test, Figure 13.

Table 2 gives a comparison between experimental and numerical results (SAP 2000) for both symmetric tests performed with regard to the displacements in the relevant joints of the truss. The values reported in Table 2 are the maximum displacement of the symmetric tests performed.

Table 2 show a good fit between the values worked out by means of the numerical model and the experimental results, with exception of the LVDT-2 values, all errors reported by the numerical model are under $10 \%$. Experimental results for the global vertical displacement of the truss under the king-post are clearly increase by the numerical model. This inconsistency can only be explained by the faulty connections between the king-post and the tie-beam. The heel strap must introduce a "frictional stiffness" which reduces the mid-span deformations of the tie-beam when the truss is loaded. Ideally, in the tie-beam/post connections it shall be used a heel strap, nailed only in the post, suspending the tie-beam with a connection without bending-stiffness.

The calibration process of the numeric model shows that during the experimental campaign a stiffness updating of the connections occurs (Table 3). This conclusion, confirmed by the test results, is due essentially to the fact of the connections were originally dismantled (significant gaps existed between the metal devices and the joints). 
Table 2. Comparison between numerical values ( $\mathrm{Nu}$.) and tests results (Exp.). Error (Er.) express in (\%).

\begin{tabular}{|c|c|c|c|c|c|c|c|c|}
\hline \multicolumn{9}{|c|}{ Test 3F-C } \\
\hline \multicolumn{9}{|c|}{ Global displacements (mm) } \\
\hline \multicolumn{3}{|c|}{ LVDT-1 } & \multicolumn{3}{|c|}{ LVDT-2 } & \multicolumn{3}{|c|}{ LVDT-3 } \\
\hline Exp. & $\mathrm{Nu}$. & Er. & Exp. & $\mathrm{Nu}$. & Err. & Exp. & Nu. & Err. \\
\hline 15.4 & 15.5 & 0.21 & 12.0 & 13.8 & 14.6 & 10.9 & 10.0 & 8.14 \\
\hline
\end{tabular}

Relative displacements - tie-beam/posts connections (mm)

\begin{tabular}{|c|c|c|c|c|c|c|c|c|}
\hline \multicolumn{3}{|c|}{ DG-3 } & \multicolumn{3}{|c|}{ LVDT-5 } & \multicolumn{3}{|c|}{ DG-4 } \\
\hline Exp. & $\mathrm{Nu}$. & Er. & Exp. & $\mathrm{Nu}$. & Err. & Exp. & $\mathrm{Nu}$. & Err. \\
\hline 0.64 & 0.59 & 7.81 & 0.36 & 0.35 & 3.70 & 0.18 & 0.18 & 2.22 \\
\hline
\end{tabular}

Relative displacements - rafters/tie-beam connections (mm)

\begin{tabular}{|c|c|c|c|c|c|}
\hline \multicolumn{3}{|c|}{ DG-5 } & \multicolumn{3}{|c|}{ DG-6 } \\
\hline Exp. & $\mathrm{Nu}$. & Er. & Exp. & $\mathrm{Nu}$. & Err. \\
\hline 9.48 & 8.53 & 10.0 & 0.34 & 0.35 & 4.12 \\
\hline
\end{tabular}

\section{Test 5F-S}

Global displacements ( $\mathrm{mm}$ )

\begin{tabular}{|c|c|c|c|c|c|c|c|c|}
\hline \multicolumn{3}{|c|}{ LVDT-1 } & \multicolumn{3}{|c|}{ LVDT-2 } & \multicolumn{3}{|c|}{ LVDT-3 } \\
\hline Exp. & $\mathrm{Nu}$. & Er. & Exp. & $\mathrm{Nu}$. & Err. & Exp. & $\mathrm{Nu}$. & Err. \\
\hline 7.34 & 6.89 & 6.12 & 5.63 & 6.63 & 17.7 & 5.96 & 5.59 & 6.20 \\
\hline
\end{tabular}

Relative displacements - tie-beam/posts connections (mm)

\begin{tabular}{|c|c|c|c|c|c|c|c|c|}
\hline \multicolumn{3}{|c|}{ DG-3 } & \multicolumn{3}{|c|}{ LVDT-5 } & \multicolumn{3}{|c|}{ DG-4 } \\
\hline Exp. & $\mathrm{Nu}$. & Er. & Exp. & $\mathrm{Nu}$. & Err. & Exp. & $\mathrm{Nu}$. & Err. \\
\hline 0.14 & 0.14 & 2.86 & 0.09 & 0.09 & 7.37 & 0.06 & 0.06 & 0.00 \\
\hline
\end{tabular}

Relative displacements - rafters/tie-beam connections (mm)

\begin{tabular}{lllllll}
\hline$D G-5$ & \multicolumn{5}{l}{$D G-6$} \\
\cline { 1 - 2 } \cline { 5 - 6 } Exp. & Nu. & Er. & & Exp. & Nu. & Err. \\
\hline 0.05 & 0.05 & 1.82 & 0.10 & 0.10 & 2.00 \\
\hline
\end{tabular}

When using the numeric models calibrated for the case of symmetric tests under non-symmetric loading conditions, a significant discrepancy is obtained between the numeric and experimental results. In
Table 3. Axial stiffness values $(\mathrm{kN} / \mathrm{m})$ used in the numerical model.

\begin{tabular}{lrrrrr}
\hline Test & \multicolumn{1}{c}{ DG-5 } & DG-6 & DG-3 & DG-4 & LVDT-5 \\
\hline 3F-C & 2900 & 74002 & 2000 & 2400 & 3200 \\
5F-S & 721155 & 374000 & 1000 & 31500 & 10200 \\
\hline
\end{tabular}

particular, the connections between the tie-beam and the posts, recorded by DG-3, DG-4 and LVDT-5 are sensible to the connections rotational stiffness.

\section{CONCLUSIONS}

The work results highlight the importance of the in situ experimentation, to assess the global behavior of traditional timber trusses, identify the critical areas, to plan the upgrade interventions and to quantify their effects.

Experimentation gave an insight of the truss behavior hardly reachable otherwise. The effects of the incorrect truss configuration for the roof span, the faulty connections geometry and the existing gaps in the joints in the overall behavior of the truss tested were assessed.

The numeric model implemented through a general purpose and very simple FE code (SAP 2000) has proved to be an effective and accurate method of modeling timber truss behavior, on condition that a semi-rigid behavior of the traditional connections is assumed. In this work, only the symmetric tests were modeled because the calibration process of the rotation stiffness models for the Portuguese traditional timber connections case is not yet finished. However, this fitting process must be accomplished in the next couple of months.

\section{ACKNOWLEDGMENTS}

Authors would like to acknowledge the cooperation of Adico industry (Arch. Luis Dias and Fernando) and José Manuel in the experimental campaign.

The first author gratefully acknowledges the Portuguese Foundation for Science and Technology, for his $\mathrm{PhD}$ grant SFRH/BD/18515/2004. The research described in this paper was conducted with financial support of the Portuguese Foundation for Science and Technology (POCI/ECM/56552/2004).

This work has been carried out with a partial financial contribution of the Italian Earthquake Engineering Laboratory Network (RELUIS), within the research program carried out for the Italian Agency for Emergency Management. 


\section{REFERENCES}

Branco J.M., Cruz P.J.S., Piazza M. \& Varum H. 2006. Portuguese Traditional Timber Roof Structures, In WCTE 2006 - World Conference on Timber Engineering, 6-10 August, Portland, Oregon, USA.

Branco J.M., Cruz P.J.S. \& Piazza M. 2008. Diagnosis and analysis of two king-post trusses, In SAHC 2008: Structural Analysis of Historical Constructions, Bath, UK, 02-04 July.

Candelpergher L. \& Piazza M. 2001. Mechanics of traditional connections with metal devices in timber roof structures. In Proceedings of the Seventh International Conference STREMAH 2001, Bologna, Italy.

Del Senno M. \& Piazza M. 2003. Behaviour and rehabilitation of queen post timber trusses. A case study. In STREMAH 2003: Structural Studies, Repairs and Maintenance of Heritage Architecture VIII, May, Halkidiki, Greece.

LNEC 1997. Timber for structures - Maritime pine for structures. LNEC (eds), Ficha M2. ISSN 0873-6472, Lisbon, 12 p. (only available in Portuguese).

Parisi M.A. \& Piazza M. 2000. Mechanics of plain and retrofitted traditional timber connections. Journal of Structural Engineering, ASCE; 126(12): 1395-403.

Piazza M., Brentari G. \& Riggio M.P. 2004. Strengthening and control methods for old timber trusses: the queen-post truss of the Trento theatre. In SAHC 2004. Structural Analysis of Historical Constructions, Padova, IT, II: 957-965.

SAP 2000. Static and Dynamic Finite Element Analysis of Structures. Structural Analysis Program. Computers and Structures. Inc., Advanced 9.03. California. USA. 